Bangladesh J. Bot. 48(2): 289-295, 2019 (June)

\title{
REGIONAL VARIATION IN AGRO-MORPHOLOGICAL DESCRIPTORS OF SESBANIA BISPINOSA (JACQ.) W. WIGHT
}

\author{
Sontosh C Chanda, Md Amir Hossain ${ }^{1}$, Md Mustafizur Rahman ${ }^{1}$, \\ ANM Shamsuzzaman ${ }^{2}$ and AKM Golam Sarwar* \\ Laboratory of Plant Systematics, Department of Crop Botany, Bangladesh \\ Agricultural University, Mymensingh, Bangladesh
}

Keywords: Cluster analysis, Location, Principal component analysis, Sesbania

\begin{abstract}
The effect of regional diversity on 12 agro-morphological descriptors of Sesbania bispinosa (Jacq.) W. Wight was studied. The mean sum of square varied significantly for six of these traits viz., plant height, branch number/plant, pod number/plant, pod length, seed number/pod and seed width. Among the ten regions, plants grown from seeds of Tangail, Chuadanga and Sirajganj districts of Bangladesh performed better in terms of plant height, number of branches/plant, number of pods/plant, pod length, number of seeds/pod and seed width. In principal component analysis, first six principal components (PC1, PC2, PC3, PC4, PC5 and PC6) showed Eigen value $>1$ and accounted for $85.6 \%$ of the total variance. In cluster analysis based on the studied agro-morphological descriptors, the cluster 1 consists of three regions (Chuadanga, Tangail and Jhinaidah), cluster 2 of six regions (Khulna, Mymensingh, Rangpur, Sunamganj, Gaibandha and Faridpur) and cluster 3 of only one district (Sirajganj). Considering these multivariate analyses, three different morphotypes of $S$. bispinosa could be identified from different locations.
\end{abstract}

\section{Introduction}

Sesbania, belonging to Fabaceae, is one of the most important green manure crops with multiple uses viz., mulch for moisture conservation, weed suppression, ground cover, firewood, fuel, fiber and bio-energy sources, providing live support fencing wood, raw materials for industrial uses, and in traditional agro-forestry systems (Ndoye et al. 1990, Swami et al. 2012, Sarkar et al. 2017). It also possesses medicinal importance (Gomase et al. 2012) and uses as animal feed and fodder (Shahjalal and Topps 2000, Kabir et al. 2018). Three species of the genus Sesbania viz., S. sesban (L.) Merr., S. bispinosa (Jacq.) W. Wight [syn. S. aculeata (Wild.) Poir] and S. cannabina (Retz.) Poir, are commonly called as dhaincha in Bangladesh (Ahmed et al. 2009, Sarwar et al. 2015). Among the species, S. bispinosa is the most common (Chanda et al. 2018). Sesbania species are found all over the Bangladesh and tolerant to saline and alkaline soils, and waterlogged condition. It grows well in char lands, roadsides as well as other marginal lands. The genus Sesbania can adapt up to $500 \mathrm{~m}$ height, annual temperature ranging from 20 to $30^{\circ} \mathrm{C}$ and rainfall varying from 570 to $2210 \mathrm{~mm}$. It propagates through both sexual and asexual systems.

Considering the bulky magnitude of Sesbania species, systematic breeding efforts are required to develop the plant type and economic characters of the crop. These characters are mainly relevant to environmental, morphological and physiological behaviours. Morphological dissimilarity is robustly influenced by different environments. Morphological differentiation occurs in the constant adaptation of the species in environment (Hussain and Mahmood 2004, Singhdoha et al. 2017).

*Author for correspondence: <drsarwar@bau.edu.bd>. ${ }^{1}$ Department of Genetics \& Plant Breeding, Bangladesh Agricultural University, Mymensingh, Bangladesh. ${ }^{2}$ Deputy Director, Local Government, Sirajganj, Bangladesh. 
Selection through morphological descriptors significantly influences to achieve the crop improvement programme. Dendrogram and principal component analyses (PCA) are suitable multivariate technique which helps to determine effective traits for indirect selection of superior genotypes (Lever et al. 2017, Mehraj and Shimasaki 2017).

Morphological descriptors viz., plant height, number of primary branches, seeds/pod, seed length and width, 1000-seed weight and its potential yield capacity, fluctuate due to geographical effect (Dumbre and Deshmukh 1984). The crop Sesbania has wide ecological adaptation, as a result, it is found in different types of soil, easily grow and survive in minimum practice (Heering 1995). Apart from taxonomic (/identification) research, a few studies have been carried out on the morphological variations of Sesbania species from Bangladesh (Sarwar et al. 2015, Chanda et al. 2017a, b, 2018). Morphological descriptors are strongly influenced by various environmental factors and the environment varied due to different locations (/regions). This study, therefore, was undertaken to assess the regional effect on agro-morphological descriptors of S. bispinosa.

\section{Materials and Methods}

The experiment was conducted at Field Laboratory of the Department of Crop Botany, Bangladesh Agricultural University, Mymensingh, during the year of 2016. Seeds were collected from ten different locations (districts) of Bangladesh viz., Rangpur, Gaibandha, Sirajganj, Khulna, Jhinaidah, Chuadanga, Tangail, Mymensingh, Sunamganj and Faridpur. Seeds were sown in $2.5 \times$ $2.0 \mathrm{~m}^{2}$ plot with $50 \mathrm{~cm}$ (line-line) $\times 15 \mathrm{~cm}$ (plant-plant) spacing following complete randomized design with three replications.

Twelve agro-morphological descriptors viz., plant height, number of branches/plant, inflorescence length, number of flowers/inflorescence, number of pods/inflorescence, number of pods/plant, pod length and width, number of seeds/pod, seed length and width and 1000-seed weight, were studied. Based on above mentioned agro-morphological descriptors (traits), analysis of variance (ANOVA) and cluster analysis were conducted, and a dendrogram, based on complete linkage between clusters and Euclidean distance, was built using the GenStat-10 statistical programme (http://www.biosci.global/softwar-en/genstat/). The principal component analysis (Robitzsch et al. 2018), which was computed from the eigen values of the covariance matrix, was also conducted using the "R" software package (https://cran.r-project.org/bin/windows/).

\section{Results and Discussion}

The ANOVA of Sesbania accessions collected from ten different locations for 12 agromorphological descriptors and genotypes has been presented in Table 1. The differences among genotypes for most of studied characters were highly significant for genotype, treatment and genotype-treatment interaction. Among twelve agro-morphological descriptors, the mean sum of square due to accessions of different locations showed a significant variation for six descriptors viz., plant height, number of branches/plant, number of pods/plant, pod length, number of seeds/pod and seed width (Table 1). It indicates the presence of high genetic variability in seeds collected from different districts. The significant differences among the districts (locations) studied suggested that this variability can be further utilized in crop improvement programmes. Rani $e t$ al. (2006) obtained similar results in Sesbania species. They have suggested that a huge scope in maintaining and utilizing genetic resources and initiating a sound breeding programme of this important genus. Rest of six descriptors viz., inflorescence length, number of flowers and pods/inflorescence, pod width, seed length and 1000-seed weight, showed insignificant variations (Table 1). It indicates that these descriptors might mainly be genetically controlled, and there is no or little effect of environments or locations on these descriptors. 
Plant height and number of flowers/inflorescence were the highest in plants grown from seeds of Tangail district (Fig. 1). On the other hand, number of pods/inflorescence and seed width were the highest from Chuadanga district. Moreover, inflorescence length, pod width, and seed length of the plant were the highest from Sunamganj district. Plant height and seed length were the smallest from Faridpur district (Fig. 1). This may indicate to the presence of huge variations in the genetic make-up of S. bispinosa. Plants from seeds of Gaibandha district produced the smaller inflorescence and number of flowers/inflorescence. The number of pods/inflorescence was lower from Rangpur district. Pod and seed widths were the lowest in Sirajganj district (Fig. 1). These variations in different morphological descriptors were random among the sources, might be due to the facts that genotypes initially grew under different environmental conditions (Singhdoha et al. 2017).

Table 1. ANOVA of agro-morphological descriptors of S. bispinosa.

\begin{tabular}{lllllll}
\hline Descriptors & df & Treatments & Error & CV $(\%)$ & SE & P value $(\%)$ \\
\hline Plant height $(\mathrm{m})$ & 9 & $2.7522^{* *}$ & 0.9192 & 24.38 & 0.183 & 1.1 \\
Number of branches/plant & 9 & $374.23^{* * *}$ & 16.26 & 30.99 & 1.57 & $<0.1$ \\
Inflorescence length (cm) & 9 & $2.207^{\mathrm{NS}}$ & 1.159 & 20.32 & 0.187 & 9 \\
Number of flowers/inflorescence & 9 & $4.191^{\mathrm{NS}}$ & 1.923 & 26.33 & 0.247 & 5.3 \\
Number of pods/inflorescence & 9 & $10.117^{\mathrm{NS}}$ & 8.012 & 103.59 & 0.461 & 29.7 \\
Number of pods/plant & 9 & $834.77^{* * *}$ & 29.33 & 38.09 & 2.32 & $<0.1$ \\
Pod length (cm) & 9 & $8.57^{*}$ & 3.513 & 11.12 & 0.342 & 3.2 \\
Pod width (mm) & 9 & $0.2032^{\mathrm{NS}}$ & 0.7679 & 25.73 & 0.126 & 97.9 \\
Number of seeds/pod & 9 & $26.84^{* * *}$ & 2.974 & 10.01 & 0.46 & $<0.1$ \\
Seed length (mm) & 9 & $0.03736^{\mathrm{NS}}$ & 0.0472 & 5.46 & 0.0335 & 62.6 \\
Seed width (mm) & 9 & $0.073885^{* * *}$ & 0.0035 & 6.14 & 0.0222 & $<0.1$ \\
1000-seed weight (g) & 9 & $2.739^{\mathrm{NS}}$ & 2.683 & 9.71 & 0.26 & 44.6 \\
\hline
\end{tabular}

df degree of freedom, $* * *$ indicates significant at 0.001 probability level, $* *$ indicates significant at 0.01 probability level, $*$ indicates significant at 0.05 probability level and NS $=$ Not significant.

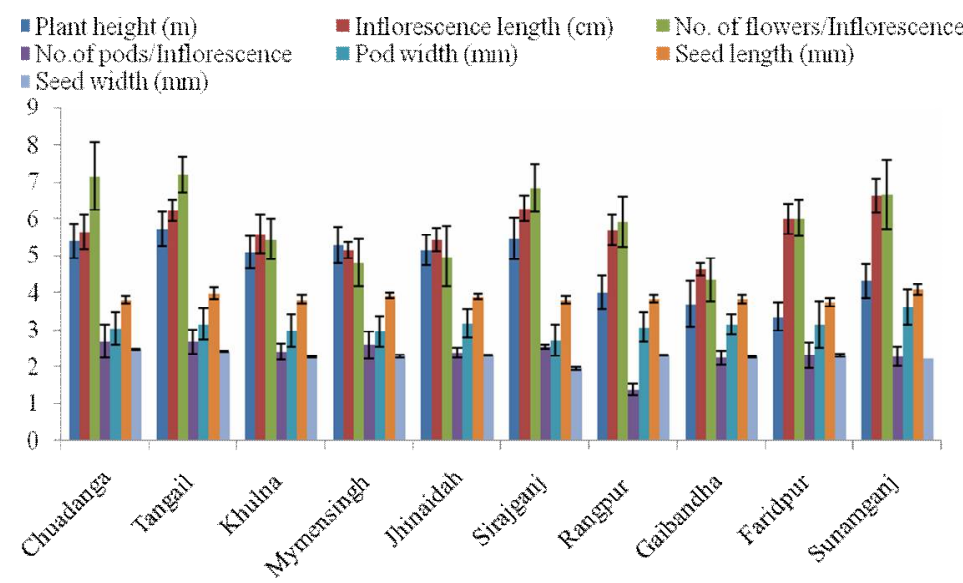

Fig. 1. Variation (in mean values) of seven agro-morphological descriptors of S. bispinosa.

Bar indicates standard error, $\mathrm{n}=10$. 
Number of branches/plant, number of seeds/pod, number of pods/plant, pod length and 1000seed weight are presented in Fig. 2. Number of branches/plant and number of seeds/pod were the highest from Tangail district. However, number of seeds/pod was the lowest from Rangpur district. Pod length was the longest from Sunamganj district. Number of pods/plant was the largest from Sirajganj district (Fig. 2). The heaviest 1000-seed was recorded from plants grown from seeds of Tangail and Chuadanga districts. Pod length and 1000-seed weight were the lowest in Sirajganj district (Fig. 2). Plant height, branch number/plant, seed number/pod, seed length and width, and 1000 -seed weight were found to be important descriptors for selecting better yield contributing parameters (Prakash et al. 2001).

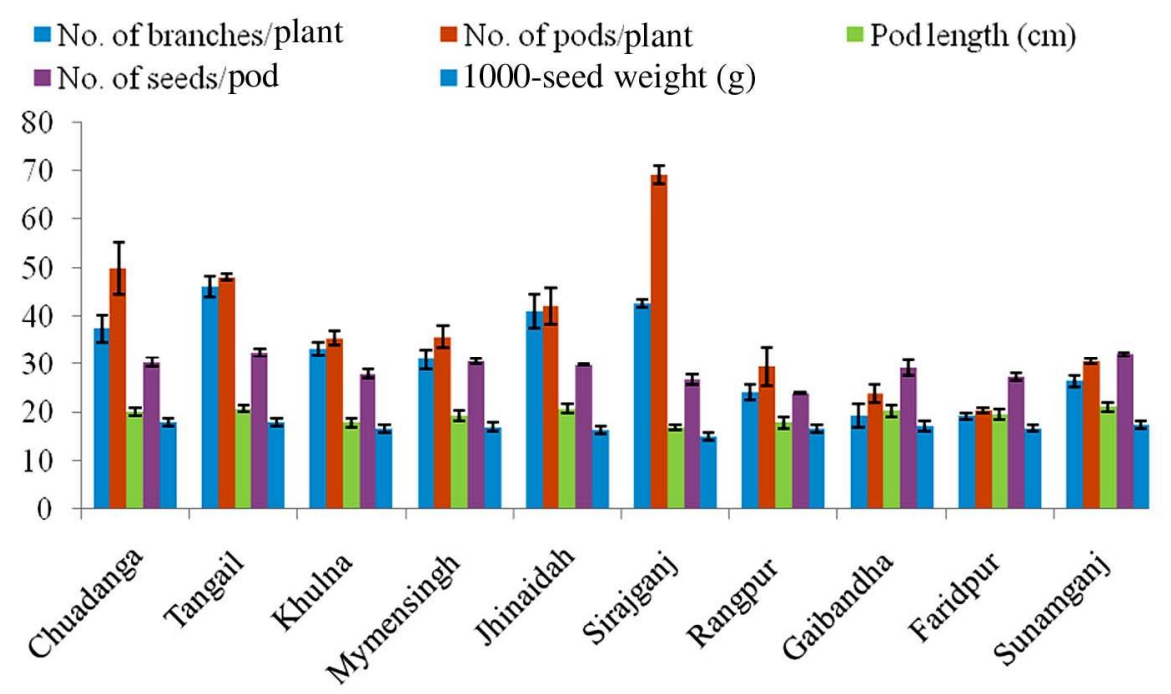

Fig. 2. Variation (in mean values) of five agro-morphological descriptors of S. bispinosa. Bar indicates standard error, $\mathrm{n}=10$.

The principal component analysis (PCA) is a helpful statistical system for providing an improved understanding of the relations among variables. It shows the structure of collection by identifying the most relevant variables, associations among germplasms, and probable outliers (Martinez-Colvo et al. 2013, Yilmaz et al. 2017). The first six principal components (PCs) possess Eigen value more than 1 and explained up to $85.6 \%$ of the total variance (Table 2). Based on the Eigen value criterion, only the PCs with Eigen value larger than 1 are considered important (Halim et al. 2013); and the coefficient value more than 0.30 was considered important for the descriptors selection (Khan et al. 2015). The first PC accounted for more than $22.8 \%$ of the total variations (Table 2). In first PC, the number of pods/plant (0.324) contributed more than other descriptors. The second PC accounted for more than $21.6 \%$ of the total variations which identified yield component viz., plant height (0.490), number of branches/plant (0.473) and number of pods/plant (0.401) were exhibited more than 0.30 values and the main characters responsible for classification (Table 2). The third PC accounted for $15.6 \%$ of total variations. All components negatively associated with yield contributing characters except inflorescence length. The fourth PC accounted $9.7 \%$ of total variations and positively associated with number of pods/inflorescence $(0.457)$. The fifth PC accounted $8.5 \%$ of total variations and associated with inflorescence length (0.337), number of pods/inflorescence (0.492) and pod width (0.616) of S. bispinosa (Table 2). The sixth PC accounted $7.4 \%$ of total variations and positively associated with pod length (0.519) and 
number of seeds/pod (0.484). The second PC is emerged as the most important component in terms of biomass (plant height and number of branches/plant) and seed yield producing descriptors (number of pods/plant) is higher than other components. This result matched with the results of Zhou et al. (2015) in tomato crop.

Table 2. Factor loading of the first six principal components with Eigen vector values.

\begin{tabular}{lcccccc}
\hline Variable & PC1 & PC2 & PC3 & PC4 & PC5 & PC6 \\
\hline Plant height (m) & 0.015 & 0.490 & -0.013 & 0.236 & -0.087 & -0.045 \\
Number of branches/plant & 0.186 & 0.473 & -0.149 & 0.141 & -0.189 & -0.133 \\
Inflorescence length (cm) & 0.294 & 0.205 & 0.077 & -0.461 & 0.337 & 0.148 \\
Number of flowers/inflorescence & 0.234 & 0.207 & -0.149 & -0.538 & 0.137 & -0.324 \\
Number of pods/inflorescence & -0.112 & 0.120 & -0.030 & 0.457 & 0.492 & -0.081 \\
Number of pods/plant & 0.324 & 0.401 & -0.007 & 0.142 & -0.122 & -0.166 \\
Pod length (cm) & -0.299 & 0.164 & -0.269 & -0.212 & 0.062 & 0.519 \\
Pod width (mm) & -0.174 & -0.008 & -0.101 & -0.098 & 0.616 & -0.296 \\
Number of seeds/pod & -0.110 & 0.283 & -0.408 & 0.041 & 0.093 & 0.484 \\
Seed length (mm) & 0.257 & -0.262 & -0.505 & 0.061 & -0.064 & -0.056 \\
Seed width (mm) & -0.366 & 0.029 & -0.312 & -0.229 & -0.319 & -0.298 \\
1000-seed weight $(\mathrm{g})$ & -0.292 & 0.045 & -0.286 & 0.180 & 0.160 & -0.313 \\
Eigen value & 3.1904 & 3.0246 & 2.1818 & 1.3544 & 1.1968 & 1.04 \\
Proportion & 0.228 & 0.216 & 0.156 & 0.097 & 0.085 & 0.074 \\
Cumulative variation $(\%)$ & 22.8 & 44.4 & 60.0 & 69.7 & 78.2 & 85.6 \\
\hline
\end{tabular}

PC1 - first principal component, PC2 - second principal component, PC3 - third principal component, PC4 - fourth principal component, PC5 - fifth principal component and PC6 - sixth principal component.

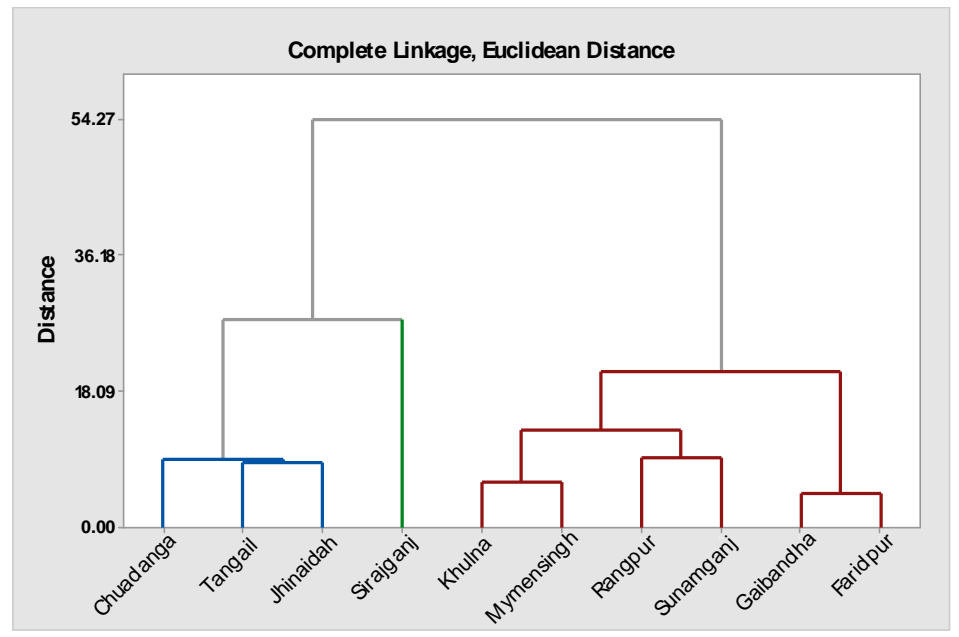

Fig. 3. Dendrogram built based on twelve agro-morphological descriptors of S. bispinosa. 
In cluster analysis based on 12 agro-morphological descriptors, complete linkage between clusters and Euclidean distance, the collected S. bispinosa accessions were grouped into three clusters (Fig. 3). The main clusters were further divided into sub-clusters. The cluster 1 consisted of three districts (Chuadanga, Tangail and Jhinaidah), cluster 2 of six districts (Khulna, Mymensingh, Rangpur, Sunamganj, Gaibandha and Faridpur) and cluster 3 of only one district (Sirajganj). The cluster analysis shows a high homogeneity within a cluster and high heterogeneity between clusters (Jain and Patel 2016). Shim et al. (2016) stated that the germplasms can be classified based on the variation of morphological descriptors using principal component and clustering analyses. Based on agro-morphological descriptors, accessions collected from Chuadanga, Tangail and Jhinaidah districts may belong to one morphotype, accessions of Khulna, Mymensingh, Rangpur, Sunamganj, Gaibandha and Faridpur districts to another morphotype and lastly the accession of Sirajganj district to another morphotype of S. bispinosa (Fig. 3).

Among 12 agro-morphological descriptors of S. bispinosa, six descriptors viz., plant height, number of branches/plant, number of pods/plant, pod length, number of seeds/pod and seed width, from different districts showed significant variation for mean sum of square. The Eigen value more than 1 was observed in first six PCs which cumulatively explained $85.6 \%$ of the total variations. Plant height, number of branches/plant and number of pods/plant are contained highest loading value in second component. In cluster analysis based on 12 agro-morphological descriptors, collected S. bispinosa accessions were grouped into 3 clusters/morphotypes. Among ten locations, the seeds (/plants) from Tangail, Chuadanga and Sirajganj districts may be emerged as better resources than seeds from other districts in terms of above mentioned six agro-morphological descriptors of S. bispinosa.

\section{Acknowledgements}

The authors acknowledge the financial support of the Ministry of Science and Technology, Government of the People's Republic of Bangladesh.

\section{References}

Ahmed ZU, Hassan MA, Begum ZNT, Khondker M, Kabir SMH, Ahmad M and Ahmed ATA 2009. Encyclopedia of Flora and Fauna of Bangladesh, Vol. 8. Angiosperms: Dicotyledons (FabaceaeLythraceae). Asiatic Soc. Bangladesh, Dhaka, pp. 1-474.

Chanda SC, Mridul A-M, Sagar A and Sarwar AKM Golam 2017a. Germination and seedling growth of Sesbania species as influenced by seed size. Progress. Agric. 28: 316-322.

Chanda SC, Prodhan AKMA and Sarwar AKM Golam 2017b. Screening of Sesbania accessions based on early biomass yield. J. Bangladesh Agril. Univ. 15: 188-192.

Chanda SC, Prodhan AKMA and Sarwar AKM Golam 2018. Morphological descriptors of seed and seedling for identification of dhaincha (Sesbania spp.) accessions. Bangladesh J. Bot. 47: 237-246.

Dumbre AD and Deshmukh RB 1984. Genetic diversity in respect of grain yield and its components in pigeon pea germplasm. J. Maharashtra Agric. Univ. 9: 310-312.

Gomase P, Gomase P, Anjum S, Shakil S and Shahnavaj KH 2012. Sesbania sesban Linn: A review on its ethno-botany, phyto-chemical and pharmacological profile. Asian J. Biomed. Pharm. 2: 11-14.

Halim MIA, Saim N, Osman R, Jasmani H and Abidin NNZ 2013. Discrimination of black ballpoint pen inks by high performance liquid chromatography. J. Anal. Sci. 17: 230-235.

Heering JH 1995. Botanical and agronomic evaluation of a collection of Sesbania sesban and related perennial species. Doctoral Thesis, Wageningen Agric. Univ., Wageningen. The Netherlands. p. 127.

Hussain A and Mahmood S 2004. Response flexibility in Trifolium alexendrinum L. of phenomenon of adaptation to special and temporal disturbed habitat. J. Biol. Sci. 4: 380-385. 
Jain SK and Patel PR 2016. Genetic diversity and principal component analysis for fodder yield and their component traits in genotypes of forage sorghum (Sorghum bicolor (L.) Moench). Ann. Arid Zone 55: 17-23.

Kabir AKMA, Moniruzzaman M, Gulshan Z, Rahman ABMM and Sarwar AKM Golam. 2018. Biomass yield, chemical content and in vitro gas production of different dhaincha (Sesbania spp.) accessions from Bangladesh. Indian J. Anim. Nutri. 35: 397-402.

Khan MA, Anjum A, Bhat MA, Padder BA, Mir ZA and Kamaluddin M 2015. Multivariate analysis for morphological diversity of bread wheat (Triticum aestivum L.) germplasm lines in Kashmir valley. J. Sci. 15: 372-376.

Lever J, Krzywinski M and Altman N 2017. Principal component analysis. Nat. Methods 14: 641-642.

Martinez-Calvo J, Naval M, Zuriaga E, Ilacer G and Badenes MI 2013. Morphological characterization of the IVIA persimmon (Diospyros kaki Thunb.) germplasm collection by multivariate analysis. Genet. Resour. Crop Evol. 60: 233-241.

Mehraj H and Shimasaki K 2017. Hierarchical cluster, euclidean distance and principal component analysis based on phenotypic characters of hosta. J. Biosci. Agric. Res. 12: 1029-1035.

Ndoye L, Tomekpe K and Dreyfus B 1990. Sesbania and Rhizobium symbiosis: nodulation and nitrogen fixation. In: Perennial Sesbania species in Agroforestry Systems, Macklin B and Evans DO (Eds). pp. 31-38. Nitrog. Fix. Tree Assoc., Waimanalo. pp. 242.

Prakash V, Rai D, Joshi V, Lal H, Sardana S and Sharma GD 2001. Evaluation of Sesbania germplasms for some green manuring traits. Indian J. Plant Genet. Resour. 14: 274-275.

Rani P, Singh S and Yadav OP 2006. Morphological characterization of Sesbania accessions using multivariate analysis. Indian J. Plant Genet. Resour. 19: 175-179.

Robitzsch A, Kiefer $\mathrm{T}$ and $\mathrm{Wu}$ M 2018. TAM: Test Analysis Modules. $\mathrm{R}$ package version 2.9. (https://CRAN.R-project.org/package=TAM).

Sarkar M, Sutradhar S, Sarwar AKM Golam, Uddin MN, Chanda SC and Jahan MS 2017. Variation of chemical characteristics and pulpability of dhaincha (Sesbania bispinosa) on location. J. Bioresour. Bioprod. 2: 24-29.

Sarwar AKM Golam, Islam A and Jahan S 2015. Characterization of dhaincha accessions based on morphological descriptors and biomass production. J. Bangladesh Agril. Univ. 13: 55-60.

Shahjalal M and Topps JH 2000. Feeding Sesbania leaves as a sole feed on growth and nutrient utilization in goats. Asian-Austral. J. Anim. Sci. 13: 487-489.

Shim KB, Shin SH, Shon JY, Kang SG, Yang WH and Heu SG 2016. Classification of a collection of sesame germplasm using multivariate analysis. J. Crop Sci. Biotech. 19: 151-155.

Singhdoha A, Dhillon RS and Bangarwa KS 2017. Assessment of genetic variation among different provenances of Acacia nilotica CPTs for seed traits. Indian J. Ecol. 44: 259-261.

Swami C, Saini S and Gupta VB 2012. Extraction of a natural dye from Sesbania aculeata plant. J. Tex. Apparel. Tech. Man. 7: 1-13.

Yilmaz B, Genç A, Cimen B, Incesu M and Yeşiloğlu T 2017. Characterization of morphological traits of local and global persimmon varieties and genotypes collected from Turkey. Turkish J. Agric. For. 41: 93102.

Zhou R, Wu Z, Cao X and Jiang FL 2015. Genetic diversity of cultivated and wild tomatoes revealed by morphological traits and SSR markers. Genet. Mol. Res. 14: 13868-13879.

(Manuscript received on 29 June, 2018; revised on 24 December, 2018) 